\title{
Experimental Study on Subjective and Objective Comprehensive Weight of Evaluation by Supervisor in Higher Vocational Education
}

\author{
Cui Liang * \\ Basic Department of Beijing Information Technology \\ College \\ Beijing Information Technology College \\ Beijing, China \\ e-mail: liangc@bitc.edu.cn
}

\author{
Xinfang Song * \\ Basic Department of Beijing Information Technology \\ College \\ Beijing Information Technology College \\ Beijing, China \\ e-mail:songxf@bitc.edu.cn \\ * Corresponding Author
}

\begin{abstract}
The approach of evaluation lies in qualitative and quantitative and stops by science. According to developmental evaluation concept and based on the indicators about quality of classroom lecture supervision and evaluation in higher vocational education, analytic hierarchy process is used to obtain subjective weights and entropy process is used to obtain objective weights. Then, matlab is used for programming to obtain the comprehensive evaluation weights for the evaluation object (teacher) respectively given by Supervisor $A$ and Supervisor $B$, so as to achieve comprehensive weight in "a combination of objective and subjective weight" to the indicators about quality of classroom lecture evaluation system. After subjective and objective comprehensive weight, lecture evaluation results will more objectively and truly reflect the teacher's practical classroom teaching, explore innovative practice path of "elevation object-oriented" lecture supervision evaluation in higher vocational education in respects of impartiality and objectivity and improve the scientific level of classroom lecture quality evaluation, which is the goals pursued for lecture supervision evaluation.
\end{abstract}

Keywords-Subjective weight; objective weight; comprehensive weight; scientific level of classroom quality evaluation; innovative practice of lecture supervision and evaluation

\section{INTRODUCTION}

According to "inspector shall implement education supervision to objectively and fairly reflect the actual situation" specified in the Education Supervision Regulations of the People's Republic of China, therefore, the implementation of objective and impartial lecture supervision evaluation is clear regulatory requirements to supervision work. Education supervision is also known as education inspection in China's history, which mainly plays a role as "imperial commissioner dedicated to education". However, the foreign education inspector mainly plays a role as "community education inspector". In 1977, Comrade Deng Xiaoping proposed the reconstruction of education supervision system, promoting the development of education supervision system. Under this circumstance, many research institutions, supervision experts and scholars have begun to learn from the Western education inspection system and study how to meet the requirements on modern supervision in consultation and education service proposed in the process of combining talent development mode with higher vocational education and developing curriculum reform in the new era by combining with China's national conditions. These research institutions, supervision experts and scholars have overcame the "subjective evaluation-based" qualitative approach used by supervision experts for lecture supervision evaluation in the past and have used the research results of mathematical model to obtain subjective weight by analytic hierarchy process or objective weight by entropy process. Then, matlab is used for programming to obtain the comprehensive evaluation weights for the evaluation object (teacher) respectively given by Supervisor A and Supervisor B, so as to achieve comprehensive weight in "a combination of objective and subjective weight" to the indicators about quality of classroom lecture evaluation system. After subjective and objective comprehensive weight, lecture evaluation results will more objectively and truly reflect the teacher's practical classroom teaching, explore innovative practice path of "elevation object-oriented" lecture supervision evaluation in higher vocational education in respects of impartiality and objectivity and improve the scientific level of classroom lecture quality evaluation, which is the goals pursued for lecture supervision evaluation and the innovative practice for promoting further scientific evaluation based on evaluation object.

\section{CONTENTS OF STUDY ON SUBJECTIVE AND OBJECTIVE COMPREHENSIVE WEIGHT}

"Survey is conducted for the purpose of solving the problem." [1] Study aims at facilitating the continuous improvement of the scientific level of evaluation to achieve qualitative evaluation proposed by current supervision experts and quantitative evaluation of data 
analysis, which is the requirement on the openness of making vocational education adapt the whole society and participate in higher vocational education quality evaluation in this era. Higher vocational education should improve its inherent competitiveness provided that scientific evaluation is used to promote the continuous improvement of the quality of higher vocational education to meet the requirements on the quality of vocational talent education caused by economic and social development. In this article, subjective analysis of supervision experts is combined with objective analysis of evaluation data to obtain comprehensive weight in "a combination of objective and subjective weight" to the indicators about quality of classroom lecture evaluation system. Practical classroom teaching can be objectively and truly reflected to promote impartiality and objectivity of lecture supervision and evaluation in higher vocational education and to explore innovative practice path for scientific evaluation. These are the missions to be completed in the study.

\section{A. Obtain subjective weight by analytic hierarchy process}

Analytic hierarchy process is a simple method to make decisions for some complex and ambiguous questions, which is particularly applicable for those problems that are difficult to complete quantitative analysis. In the mid1970s, Professor T.L.Saaty and other scholars at the University of Pittsburgh proposed a simple, flexible and practical multi-criteria decision making process - analytic hierarchy process (AHP for short). In this process, a complex problem is broken down into many composition elements and these elements are further broken down based on relation of domination to achieve hierarchy among these elements. Then, these elements are arranged together by goal layer, principle layer and index layer to form a multi-objective and multi-layer model, finally creating a ordered hierarchical structure. Then, analysis is conducted by layers. Pairwise comparison approach is used to determine relative importance of various elements in the hierarchy. Finally, comprehensive evaluation is conducted on the subject to judge and determine the sequence of all elements in respect of relative importance. Analytic hierarchy process is particularly suitable for those complex problems that are difficultly analyzed by fully using quantitative analysis approach [2].

To complete a reasonable evaluation on the teaching quality of a teacher, analysis is mainly conducted to check whether the teacher can complete various evaluation indexes during teaching and to clearly achieve high-quality lesson given by the teacher. A hierarchical analysis model is established by taking six evaluation indexes as the principle layer, including teaching preparation, teaching organization, teaching ability, teaching reform, student management and completion of teaching effect. The hierarchical structure is showed in Fig. 1.

Based on the experience of experts, pairwise comparison is conducted for these six evaluation indexes to obtain the following judgment matrix, as shown in Table 1:

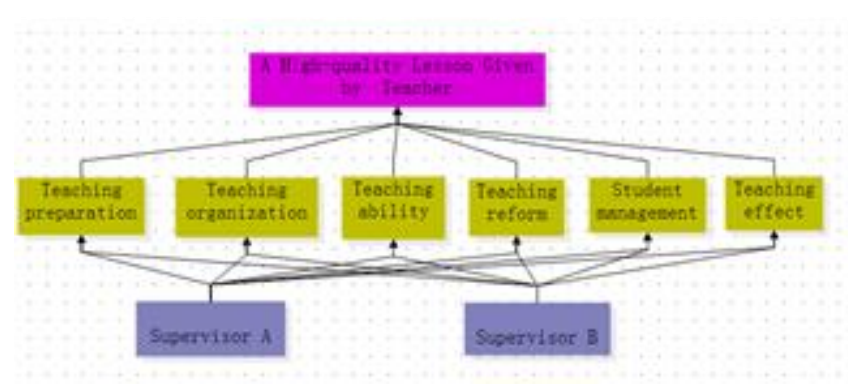

Figure 1. Hierarchical structure analysis

TABLE I. JUdGMENT MATRIX OF Six EVALUATION INDEXES

\begin{tabular}{|c|c|c|c|c|c|c|c|}
\hline $\mathrm{A}$ & $\mathrm{B}_{1}$ & $\mathrm{~B}_{2}$ & $\mathrm{~B}_{3}$ & $\mathrm{~B}_{4}$ & $\mathrm{~B}_{5}$ & $\mathrm{~B}_{6}$ & $\mathrm{~W}$ (Weight) \\
\hline $\mathrm{B}_{1}$ & 1 & $1 / 2$ & $1 / 3$ & 4 & 2 & 3 & 0.1596 \\
\hline $\mathrm{B}_{2}$ & 2 & 1 & $1 / 2$ & 5 & 3 & 4 & 0.2504 \\
\hline $\mathrm{B}_{3}$ & 3 & 2 & 1 & 6 & 4 & 5 & 0.3825 \\
\hline $\mathrm{B}_{4}$ & $1 / 4$ & $1 / 5$ & $1 / 6$ & 1 & $1 / 3$ & $1 / 2$ & 0.0428 \\
\hline $\mathrm{B}_{5}$ & $1 / 2$ & $1 / 3$ & $1 / 4$ & 3 & 1 & 2 & 0.1006 \\
\hline $\mathrm{B}_{6}$ & $1 / 3$ & $1 / 4$ & $1 / 5$ & 2 & $1 / 2$ & 1 & 0.0641 \\
\hline \multicolumn{7}{|c|}{$\lambda_{\max }=6.1233 ; C I=0.0245 ; C R=0.0197$} \\
\hline
\end{tabular}

Where, $\omega_{i}(\mathrm{i}=1, \ldots, 6)$ respectively represent the weights of six evaluation indexes, i.e. teaching preparation, teaching organization, teaching ability, teaching reform, student management and teaching effect. MATLAB code is used to obtain the weights of six evaluation indexes used in analytic hierarchy process:

$\omega_{1}=0.1596 ; \omega_{2}=0.2504 ; \omega_{3}=0.3825 ; \omega_{4}=0.0428 ;$

$\omega_{5}=0.1006 ; \omega_{6}=0.0641$.

\section{B. Obtain objective weight by entropy process}

In the comprehensive evaluation, the maximum entropy approach that uses comentropy to evaluate the degree of ordering and utility value of available system information is applicable to determine the weights of all evaluation indexes of multi-index decision-making problems. Maximum entropy counting approach is an approach to use comentropy among information theory for determining the weights of all evaluation indexes of multiindex decision-making problems. Its basic principle: for any multi-index decision-making problem, the optimal solution is selected from many feasible options by depending on decision-making information provided by various indexes of these feasible options to decision maker; the large amount of information is provided by any index, the larger contribution is made and the greater weight is obtained $^{[3]}$.

Supervision mechanism is established. Supervisor A and Supervisor B are appointed to evaluate the lesson given by a certain teacher and give the following scores in respect of six evaluation indexes, including teaching preparation, teaching organization, teaching ability, teaching reform, student management and teaching effect:

MATLAB code is used to achieve programming for scores given by Supervisor A and Supervisor B by using entropy method, so as to finally obtain weights of 
six evaluation indexes. Where: $\theta_{i}(i=1, \ldots, 6)$ respectively represent the weights of six evaluation indexes, i.e. teaching preparation, teaching organization, teaching ability, teaching reform, student management and teaching effect.

$$
\begin{aligned}
& \theta_{1}=0.0142 ; ? \theta_{2}=\quad \theta_{3}=\quad \theta_{4}= \\
& \theta_{5}=0.2201 ; \theta_{6}=0.1278 .
\end{aligned}
$$

\section{Weight of objective and subjective weighing synthetic indexes}

The ideal method to determine index weight is a comprehensive integrated weight method by in integrating objective and subjective influence factors. Generally, after comparative analysis on the existing comprehensive integrated weight methods, it shows that there are many comprehensive integrated weight methods in various forms for integrating objective and subjective influence factors. However, there are mainly three forms based on different principles: (1) Maximize the comprehensive evaluation values of each evaluation object as the objective function. This comprehensive weight method mainly includes the comprehensive integrated weight method based on unit constraints; (2) Seek consistency or compromise among all alternative weights, i.e. minimize respective deviation between the possible weight and each basic weight. This comprehensive weight method mainly includes the comprehensive integrated weight method based on game theory; and (3) Widen the difference on comprehensive evaluation value among all evaluation objects by taking the concept "decentralize comprehensive evaluation values of all decision-making solutions as much as possible" as guiding ideology. This comprehensive weight method mainly includes the comprehensive integrated weight method based on sum of squares.

Synthetic weight: wi is assumed as index weight on analytic hierarchy process and $\boldsymbol{\theta}_{\mathrm{i}}$ is assumed as index weight on entropy process, then synthetic weight is: $\varphi_{i}=\frac{w_{i} \times \theta_{i}}{\sum_{i=1}^{6} w_{i} \times \theta_{i}}$

Obtained: $\varphi_{1}=0.0226, \varphi_{2}=0.4198, \varphi_{3}=0.0611, \varphi_{4}=0.1939$ $\varphi_{5}=0.2209, \varphi_{6}=0.0817$.

Therefore, the comprehensive weights are (0.0226, $0.4198,0.0611,0.1940,0.2209$, and 0.0817). And then, comprehensive evaluation values to certain teacher given by Supervisor A and Supervisor B can be obtained as 86.1178 and 75.2606 .

\section{METHODS USED IN THE STUDY ON SUBJECTIVE AND OBJECTIVE COMPREHENSIVE WEIGHT}

Literature research method, projection technique and empirical analysis method are mainly used for lecture supervision evaluation in the experimental study.

1) Literature research method: It is a method to obtain relevant information through investigation based on contents of this experimental study, so as to fully and correctly master the studied problem. In the study, relevant literature are researched to obtain research results of analytic hierarchy process and entropy method, so as to fully and correctly understand, master and use the feasibility of subjective and objective comprehensive weights, which helps to explore effectiveness of experiment and replicability of innovative approaches.

2) Projection technique: Projection technique is used to encourage the respondents' project their potential motives, beliefs, attitudes or feelings about the concerned problems. Then, attribution analysis is depended to explore the practical significance on evaluation objects caused by subjective and objective synthetic index weight.

3) Empirical analysis: It is a social science research method to inference and illustrates examples or experience required for verification on the theory by using a range of analytical tools and starting from discipline reality or current society. For example, qualitative and quantitative analysis is one of the analytical tools used during empirical analysis.

\section{PURPOSE OF MAKING STUDY ON SUBJECTIVE AND OBJECTIVE COMPREHENSIVE WEIGHT}

Development evaluation concept is used to achieve the guidance, selection, impartiality and objectivity of lecture supervision evaluation in higher vocational education, so that lecture supervision evaluation results can more objectively and truly reflect the teacher's practical classroom teaching, which is the goals pursued for lecture supervision evaluation. On the one hand, depending on qualitative evaluation provided by supervision experts, real-time evaluation is conducted on teachers' classroom teaching behavior. On the other hand, quantitative evaluation on various index weights obtained by different experts is analyzed to conduct oriented evaluation on teachers' classroom teaching behavior in future. Finally, a combination of quantitative and qualitative evaluation is done to obtain comprehensive evaluation values by integrating qualitative evaluation provided by supervision experts with objective evaluation based on data analysis. It is a more scientific developmental evaluation by opposing against one evaluation method for the purpose of conducting guidance and selection on teachers' classroom teaching behavior, improving the level of impartiality and objectivity of evaluation and promoting teachers to improve teaching level, continue to explore teaching reform and meet the requirements on the quality of higher vocational education from the society and demands from enterprises and students. It is also is the requirement on the openness of making vocational education adapt the whole society and participate in higher vocational education quality evaluation in this era. To improve the competitiveness, higher vocational education must depend on scientific evaluation to promote the continuous improvement of quality of higher vocational education, so as to meet the requirements on the quality of vocational talent education caused by economic and social development. 


\section{ANALYSIS ABOUT RESULTS OF STUDY ON SUBJECTIVE AND OBJECTIVE COMPREHENSIVE WEIGHT}

The above analysis hierarchy process is used to obtain subjective weights, while entropy process is used to obtain objective weights. The synthetic index weight is obtained from synthesis of subjective and objective weights. Then, the calculated specific comprehensive evaluation results to lecture supervision evaluation on certain teacher are as follows: It is assumed that full-time Supervisor A and Supervisor B inspect the lesson of certain teacher and both supervisors give the following scores for lecture supervision evaluation on certain teacher in respects of six evaluation indexes, as shown in Table 2, the specific comprehensive evaluation scores to certain teachers are shown in Table 3.

TABLE II.

LIST OF LECTURE SUPERVISION EVALUATION SCORES

\begin{tabular}{|c|c|c|c|c|c|c|}
\hline $\begin{array}{c}\text { Evaluation } \\
\text { Factor }\end{array}$ & $\begin{array}{c}\text { Teaching } \\
\text { Preparation (15) }\end{array}$ & $\begin{array}{c}\text { Teaching } \\
\text { Organization (25) }\end{array}$ & $\begin{array}{c}\text { Teaching } \\
\text { Ability (25) }\end{array}$ & $\begin{array}{c}\text { Teaching } \\
\text { Reform (10) }\end{array}$ & $\begin{array}{c}\text { Student } \\
\text { Management (15) }\end{array}$ & $\begin{array}{c}\text { Teaching } \\
\text { Effect (10) }\end{array}$ \\
\hline $\begin{array}{c}\text { Supervisor } \\
\text { A }\end{array}$ & 90 & 95 & 85 & 90 & 94 & 95 \\
\hline $\begin{array}{c}\text { Supervisor } \\
\text { B }\end{array}$ & 85 & 78 & 80 & 65 & 75 & 80 \\
\hline
\end{tabular}

TABLE III. EXPERIMENT WEIGHTS OF SUBJECTIVE AND OBJECTIVE COMPREHENSIVE WEIGHING ON LECTURE SUPERVISION AND EVALUATION ON CERTAIN TEACHER

\begin{tabular}{|c|c|c|c|c|c|c|c|}
\hline $\begin{array}{c}\text { Evaluation } \\
\text { Factors }\end{array}$ & $\begin{array}{c}\text { Teaching } \\
\text { Preparation(15) }\end{array}$ & $\begin{array}{c}\text { Teaching } \\
\text { Organization(25) }\end{array}$ & $\begin{array}{c}\text { Teaching } \\
\text { Ability (25) }\end{array}$ & $\begin{array}{c}\text { Teaching } \\
\text { Reform(10) }\end{array}$ & $\begin{array}{c}\text { Student } \\
\text { Management(15) }\end{array}$ & $\begin{array}{c}\text { Teaching } \\
\text { Effect(10) }\end{array}$ & Average Score \\
\hline $\begin{array}{c}\text { Supervisor } \\
\text { A }\end{array}$ & 90 & 87 & 77 & 89 & 90 & 70 & 83.83 \\
\hline $\begin{array}{c}\text { Supervisor } \\
\text { B }\end{array}$ & 85 & 78 & 80 & 65 & 75 & 80 & 77.17 \\
\hline Average & 87.5 & 82.5 & 78.5 & 77 & 82.5 & 75 & 80.5 \\
\hline $\begin{array}{c}\text { Subjective } \\
\text { Weight }\end{array}$ & 0.1596 & 0.2504 & 0.3825 & 0.0428 & 0.1006 & 0.0641 & Total 1 \\
\hline $\begin{array}{c}\text { Objective } \\
\text { Weight }\end{array}$ & 0.0142 & 0.168 & 0.016 & 0.454 & 0.22 & 0.1278 & Total 1 \\
\hline $\begin{array}{c}\text { Comprehensive } \\
\text { Weight }\end{array}$ & 0.0226 & 0.4198 & 0.061 & 0.1947 & 0.2209 & 0.08175 & Total 1 \\
\hline $\begin{array}{c}\text { *Score Given } \\
\text { by Supervisor A }\end{array}$ & 2.0354 & 36.5222 & 4.7026 & 17.2578 & 19.8773 & 5.7224 & $\begin{array}{c}\text { Comprehensive } \\
\text { Weight Given } \\
\text { by Supervisor A } \\
86.1178\end{array}$ \\
\hline $\begin{array}{c}* \text { Score Given } \\
\text { by Supervisor B } \\
\text { Comprehensive } \\
\text { Weight }\end{array}$ & 1.9224 & 32.7441 & 4.8858 & 12.604 & 16.5644 & 6.5399 & $\begin{array}{c}\text { Comprehensive } \\
\text { Weight Given } \\
\text { by Supervisor B } \\
75.2606\end{array}$ \\
\hline $\begin{array}{c}\text { Integrated } \\
\text { Average }\end{array}$ & 1.9789 & 34.6332 & 4.7941 & 14.9308 & 18.2209 & 6.1311 & 80.6892 \\
\hline
\end{tabular}

According to the above results, if a single method is used for evaluation, the average score given by Supervisor A (83.83) and Supervisor B (77.17) is 80.5; if subjective and objective synthetic weighting method is used for evaluation, the average score given by Supervisor A (86.12) and Supervisor B (75.26) is 80.69; the average weight difference is 0.19 . However, comprehensive weights clearly show the ranking of the level of the teacher's classroom teaching ability and the level that the teacher should reach from high to low, i.e. teaching organization (0.4198), student management (0.2209), teaching reform $(0.1940)$, teaching effect $(0.0818)$, teaching ability $(0.0611)$ and teaching preparation (0.0226). However, the score for teacher's all abilities are lower than 0.5 , indicating that the teacher should focus on solving the problems of teaching preparation and improve the responsibility and then enhance the strength in improvement of teaching ability, teaching effect and teaching reform in future teaching. Meanwhile, the teacher does well in teaching organization and student management rather than other respects. Such analysis has higher guidance and convincing than just seeing evaluation score due to show specific, objective, intuitive and clear features of data and information. It is easier to make evaluation object accept such analysis than many descriptive words. Evaluation object can pay attention to improve his/her classroom teaching in future only after accepting evaluation results. Certainly, except for those teachers that do not want to change themselves, all aggressive teachers can continue to improve and enhance their abilities in teaching by facing objective analysis. Such analysis also plays a positive role in promoting the communication between evaluator and evaluation object, reducing non-objective evaluation caused by many human factors. In this sense, the approach of evaluation lies in qualitative and quantitative and stops by science. The essence of education is to promote the comprehensive development of human [6], while the essence of evaluation is to promote the scientific development of teachers. As long as the establishment of system of subjective and objective comprehensive weight of evaluation about lecture supervision in higher vocational education is achieved by starting from scientific and developmental evaluation concept, comprehensive weight must play an active role in promoting the quality of higher vocational classroom teaching and boosting the continuous improvement of scientific level of evaluation, so as to provide better service for higher vocational education reform. 


\section{ACKNOWLEDGMENT}

The paper is supported by the Research Fund for the Doctoral Program (New Teachers), Ministry of Education of China under Grant No. 20121103120032, Humanity and Social Science Youth foundation of Ministry of Education of China under Grant No. 13YJCZH065, General Program of Science and Technology Development Project of Beijing Municipal Education Commission of China under Grant No. km201410005012.

\section{REFERENCES}

[1] Mao Tse-tung, Oppose Book Worship, Anthology of Thinking and Working Methods, [M], Beijing, CPC Central Party Literature Publisher, May 1990
[2] Song Xinfang, Application of AHP in the Subway Station Settings, [J], Journal of XingTai Polytechnic College, May 2014, pp.93-97.

[3] Lu Tianchao, KangKai, The application of entropy method and AHP in weight determining, [J],Software Development and Design, September 2009,pp.19-21.

[4] Liang Cui, Harmonious Development on Dual Subject of Teachers and Students, [J], Journal of Beijing Administrative College, May 2007, pp.78-81

[5] Marx, Theses on Feuerbach, Karl Marx and Frederick Engels (Chinese Version), Volume 3, P3-P6, [M], Beijing, People's Publisher, Edition 1, December 1960

[6] Uhomlinski, Suggestions to Teachers (Volume II), [M], Du Diankun, Translated Version, Beijing, Education Science Press, 1981, pp.419-420

[7] M. Young, The Technical Writer's Handbook. Mill Valley, CA: University Science, 1989. 